\title{
STRUKTUR POPULASI BEKANTAN (NASALIS LARVATUS) DI RAWA GELAM
}

\author{
Structure of Bekantan Population in Cajuputi Swamp \\ ReniSrimulyaningsih ${ }^{1)}$; Maiser Syaputra ${ }^{2)}$ \\ 1) Fakultas Kehutanan Universitas Minaya Mukti \\ 2) Jurusan Kehutanan Fakultas Pertanian Universitas Mataram \\ *Email : reni.srimulyaningsih@unwim.ac.id
}

Diterima : 09/05/2020, Direvisi : 21/01/2020, Diterbitkan 01/03/2021

\begin{abstract}
Proboscis monkey (Nasalis larvatus) is one of the endemic species of Borneo Island and is legally protected by both Indonesian Government Regulations and international regulations, because this animal is included in the category of endangered species. Currently the proboscis monkey population continues to decline and there is not much information about the structure of the proboscis monkey population, especially in the Gelam swamp. The purpose of this study was to analyze the population structure of the proboscis monkey. The research method used is the river survey method and concentration count. Based on the results of the study, the number of proboscis monkey populations in the Gelam Swamp that can be counted directly in the field are 190 individuals, which are divided into 9 groups, consisting of 8 babies, 30 children, 21 juvenile males, 34 male deawasa, 20 juvenile females, and 77 adult female. The sex ratio of the proboscis monkey population in the Gelam swamp was 1:1,8 and only one group was close to the average ratio in general, namely group 4 with a sex ratio of 1: 4 . The age structure of the proboscis monkey population in the Gelam swamp shows a declining trend of population. This can be seen from the condition that the number of young proboscis monkeys is less than the number of adult and young proboscis monkeys.
\end{abstract}

Keywords; Population, Cajuputi swap forest, Proboscis monkey

\begin{abstract}
ABSTRAK
Bekantan (Nasalis larvatus) merupakan salah satu satwa endemik Pulau Borneo dan dilindungi secara hukum baik oleh Peraturan Pemerintah Indonesia maupun peraturan internasional, hal ini karena satwa ini termasuk kategori satwa terancam punah. Saat ini populasi bekantan terus mengalami penurunan dan belum banyak informasi mengenai struktur populasi bekantan khususnya di rawa gelam. Tujuan penelitian ini adalah untuk menganalisis struktur populasi bekantan. Metode penelitian yang digunakan adalah metode river survey dan concentration count. Berdasarkan hasil penelitian, jumlah populasi bekantan di rawa gelam yang dapat dihitung secara langsung di lapangan berjumlah 190 individu, yang terbagi ke dalam 9 kelompok, terdiri dari 8 bayi, 30 anak, 21 jantan remaja, 34 jantan deawasa, 20 betina remaja, dan 77 betina dewasa. Nisbah kelamin populasi bekantan di rawa gelam 1: 1,8 dan hanya satu kelompok yang mendekati rata-rata nisbah kelamin pada umumnya, yaitu kelompok 4 dengan nisbah kelamin 1:4. Struktur umur populasi bekantan di rawa gelam menunjukkan tren poplasi menurun. Hal ini terlihat dari kondisi jumlah bekantan anakan yang lebih sedikit jika dibandingkan dengan jumlah bekantan umur dewasa dan muda.
\end{abstract}

Kata kunci; Populasi, Rawa gelam, Bekantan 


\section{PENDAHULUAN}

Pulau Borneo memiliki salah satu keanekaragaman hayati satwa bernilai penting yaitu Bekantan (Nasalis larvatus). Satwa ini bersifat endemik, yang artinya hanya dapat ditemukan secara terbatas di wilayah tertentu. Karena penyebaran dan populasinya yang terbatas ini, Bekantan dilindungi secara hukum oleh pemerintah Indonesia melalui Peraturan Pemerintah Nomor 106 tahun 2018 tentang Jenis Tumbuhan dan Satwa Dilindungi. Secara internasional, Bekantan masuk ke dalam kategori terancam punah (Endangered) berdasarkan International Union for Conservation of Natureand Natural Resources (IUCN) dan Appendix I CITES (Convention on International Trade in Endangered Species of Wild Fauna and Flora) yang artinya tidak boleh diperdagangkan secara bebas. Bekantan termasuk spesies yang.

Populasi Bekantan dari tahun ke tahun terus mengkhawatirkan, hal ini disebabkan oleh faktor perubahan habitat dan alih fungsi lahan yang menyebabkan populasi satwa ini di alam mengalami penurunan (IUCN, 2020). Hal ini diperkuat oleh pernyataan MacKinnon (1987) yang menyatakan bahwa berkurangnya luasan dan penurunan kualitas habitat berdampak nyata pada penurunan populasi bekantan. Atmoko et al., (2013) menambahkan bahwa setidaknya telah terjadi penurunan populasi bekantan sebanyak 50$80 \%$ di alam. Supriatna dan Wahyono (2000) menguatkan bahwa faktor kerusakan habitat merupakan penyebab utama berkurangnya jumlah bekantan di alam liar dan hampir $47 \%$ habitat bekantan telah menghilang. MacKinnon (1987) menyatakan bahwa populasi bekantan diperkirakan berjumlah 260.950 ekor, data ini diperbaharui oleh Bismark (1995) yang menyatakan bahwa pada tahun 1995 populasi Bekantan menurun menjadi sekitar 114.000 ekor. Penurunan populasi ini sudah seharusnya menjadi perhatian semua pihak untuk tetap menjaga habitat bekantan.

Bekantan dapat dijumpai di berbagai tipe habitat seperti kawasan hutan mangrove, rawa air tawar, hutan tepian sungai, rawa gelam hingga perkebunan karet (Alikodra dan Srimulyaningsih, 2015). Salah satu tipe habitat Bekantan yang datanya belum terdokumentasi dengan baik berada pada ekosistem rawa gelam di Kabupaten Tapin, Kalimantan Selatan. Habitat ini berada di sekitar kanal Sungai Puting yang masuk ke dalam wilayah kerja PT AGM (Antang Gunung Meratus). Sungai yang dijadikan sebagai kanal ini merupakan rawa yang didominasi oleh tanaman gelam atau Malaleuca cajuputi. Rawa ini juga merupakan sumber mata pencaharian masyarakat sekitar, masyarakat memanfaatkan rawa untuk mencari ikan, berburu burung, berladang maupun mengambil kayu bakar. Keberadaan masyarakat dan adanya intervensi masyarakat dalam memanfaatkan rawa gelam ini secara tidak langsung mempengaruhi kelangsungan hidup Bekantan. Hal ini terlihat dari adanya aktivitas perambahan dan pembukaan ladang dengan cara membakar sehingga mengakibatkan berkurangnya pohon pakan, pohon tidur dan pohon yang berfungsi sebagai tempat istirahat bekantan.

Melihat pentingnya keberadaan Bekantan dan kondisinya yang semakin terdesak di rawa gelam, maka penelitian ini menjadi penting untuk dilakukan. Tujuan dari penelitian ini adalah untuk menganalisis struktur populasi bekantan meliputi ukuran kelompok, perbandingan rasio kelamin, dan struktur umur. Hasil penelitian ini diharapkan dapat menjadi dasar dalam perumusan upaya konservasi bekantan untuk mendukung pelestarian satwa tersebut.

\section{METODE}

\section{Lokasi Penelitian}

Penelitian ini dilaksanakan di ekosistem rawa gelam yang berada di sepanjang kanal pengangkutan batubara wilayah kerja PT AGM. Berdasarkan peta kerja PT AGM, kanal ini merupakan gabungan antara dua sungai, yaitu Sungai Mati/Sungai Muning dan Sungai Puting dengan panjang keseluruhan 28,5 kilometer. Potensi kelompok bekantan yang 
diteliti adalah bekantan yang berada di sebelah kiri sungai. Secara administratif pemerintahan daerah lokasi penelitian terletak di delapan desa dan empat kecamatan, yaitu empat desa di Kecamatan Tapin Selatan (Desa Tatakan, Desa Suato Tatakan, Desa Tandui, dan Desa Lawahan), dua desa di Kecamatan Tapin Tengah (Desa Bahalang dan Desa Sukaramai), satu desa di Kecamatan Candilaras Selatan (Desa Baringin), dan satu desa di Kecamatan Candilaras Utara (Desa Margasari). Waktu penelitian dilakukan pada tahun 2013 pada dua musim, yaitu pada saat musim penghujan (bulan Januari sampai Maret) dan pada saat musim kemarau (bulan April sampai Juni).

\section{Survei Populasi}

Data penelitan yang dikumpulkan meliputi: jumlah individu, kepadatan, nisbah kelamin (sex ratio) dan struktur umur. Jumlah individu dan kepadatan diukur menggunakan metode river survey (Sha et al, 2008). Pengamatan dilakukan dengan bantuan binokuler dan kamera. Penelitian dilakukan mulai jam 06.00 pagi sampai dengan jam 18.00 selama 90 hari pengamatan. Penghitungan populasi dilakukan dengan menggunakan metode tekonsentrasi atau concentration count (Alikodra, 2002). Data nisbah kelamin dan struktur umur diperoleh dengan cara mengidentifikasi jenis kelamin dan kelas umur pada bekantan berdasarkan ciri morfologi yang tampak. Bekantan jantan dewasa memiliki hidung yang relatif besar, alat kelamin eksternal, terdapat warna putih berbentuk segi tiga pada bagian pinggul serta otot yan berkembang dengan baik. Betina berukuran relatif lebih kecil, puting susu jelas serta hidung lebih kecil dan runcing (Bennett dan Sebastian, 1988; Yeager, 1989; Bismark, 2005).

Struktur umur selain dibedakan berdasarkan ukuran tubuh juga dapat diduga berdasarkan panjang ekor. Menurut Bennet dan Sebastian (1988), nilai E/Td untuk kelas umur dewasa dan setengah dewasa adalah 1, sedangkan untuk remaja, panjang ekor adalah $1 \frac{1}{3}$ tinggi badan, sedangkan bayi ekornya lebih dari $1 \frac{3}{4}$ tinggi duduk. Struktur umur juga dapat dibedakan dari warna rambut, yaitu untuk dewasa biasanya berwarna coklat keemasan kusam, remaja coklat keemasan agak kusam, sedangkan bayi yang baru lahir hitam kecoklatan sampai coklat emas agak kemerahan atau lebih terang dibanding dengan umur remaja dan dewasa.

\section{Analisa Data}

Data hasil pengamatan di analisa secara deskriptif - kuantitatif. Analisa deskriptif dilakukan dengan cara menyederhanakan, merata-ratakan, meringkas, dan menggolongkan data yang bertujuan untuk menajamkan dan mengorganisasi data sedemikian rupa sehingga didapat data utama yang menjadi pokok penelitian serta mendapatkan kesimpulan akhir (Sugiyono, 2010). Sedangkan analisa kuantitatif adalah analisa yang menggunakan pendekatan fenomena melalui pengukuran objektif dan menganalisis secara numerikal yang bersifat spesifik, jelas dan rinci (Prastowo, 2016). Analisa kuatitatif terdiri dari kepadatan dan nisbah kelamin. Kepadatan diperoleh dengan membagi jumlah total individu yang ditemukan dengan luas areal contoh yang diamati (Tobing, 2008) dengan persamaan yang digunakan:

Keterangan:

$$
d=N / L j \times P j
$$

$\mathrm{d}=$ Densitas (kepadatan)

$\mathrm{N}=$ Total individu yang terdeteksi di dalam jalur

$\mathrm{Lj}=$ Lebar jalur pengamatan

$\mathrm{Pj}=$ Panjang jalur pengamatan

Nisbah kelamin dihitung dari perbandingan jumlah jantan dewasa dan betina dewasa (Santosa dan Sitorus, 2008) dengan persamaan:

$$
S=Y / X
$$


Keterangan:

$\mathrm{S}=$ Sex ratio

$\mathrm{Y}=$ Jumlah jantan dewasa

$\mathrm{X}=$ Jumlah betina dewasa

\section{HASIL dan PEMBAHASAN,}

\section{Jumlah dan Kepadatan Populasi}

Populasi bekantan di rawa gelam berdasarkan hasil perhitungan secara langsung di lapangan berjumlah 190 individu, terbagi ke dalam 9 kelompok, terdiri dari 8 bayi, 30 anak, 21 jantan remaja, 34 jantan deawasa, 20 betina remaja, dan 77 betina dewasa (Tabel 1). Jumlah kelompok dengan ukuran besar adalah kelompok 6 dan 8 masing-masing sebanyak 48 dan 47 individu. Besarnya ukuran populasi ini diduga karena habitat Bekantan kelompok 6 dan 8 berada dalam kondisi yang baik, sehingga kebutuhan pohon pakan, pohon tidur dan pohon untuk aktivitas lainnya masih tersedia. Selain itu lokasi ini juga jauh dari aktivitas masyarakat, berdasarkan hasil pengamatan tidak terlihat adanya aktivitas masyarakat seperti memancing, bercocok tanam dan menebang kayu gelam. Selanjutnya, kelompok Bekantan paling kecil adalah kelompok 9 dengan jumlah 4 individu. Rendahnya ukuran kelompok 9 ini diduga karena faktor habitat serta kondisi vegetasi yang kurang baik, terlihat dari vegatasi pada wilayah ini yang tumbuh jarang, selain itu di wilayah ini dapat ditemukan berbagai macam interaksi masyarakat seperti disebutkan di atas.

Tabel 1. Jumlah populasi bekantan di rawa gelam

Table 1. Number population of bekantan in cajuputi swamp

\begin{tabular}{|c|c|c|c|c|c|c|c|}
\hline \multirow{2}{*}{ Kelompok } & \multirow{2}{*}{ B } & \multirow{2}{*}{ A } & \multicolumn{2}{|c|}{ Jantan } & \multicolumn{2}{|c|}{ Betina } & \multirow{2}{*}{$\begin{array}{c}\text { Jumlah Per } \\
\text { kelompok }\end{array}$} \\
\hline & & & $\mathbf{R}$ & D & $\mathbf{R}$ & D & \\
\hline 1 & 0 & 1 & 1 & 1 & 2 & 5 & 10 \\
\hline 2 & 0 & 2 & 3 & 4 & 2 & 4 & 15 \\
\hline 3 & 0 & 0 & 2 & 4 & 2 & 2 & 10 \\
\hline 4 & 5 & 6 & 0 & 4 & 0 & 16 & 31 \\
\hline 5 & 0 & 1 & 0 & 1 & 1 & 2 & 5 \\
\hline 6 & 0 & 11 & 5 & 7 & 5 & 20 & 48 \\
\hline 7 & 2 & 5 & 3 & 4 & 2 & 4 & 20 \\
\hline 8 & 1 & 4 & 6 & 8 & 6 & 22 & 47 \\
\hline 9 & 0 & 0 & 1 & 1 & 0 & 2 & 4 \\
\hline Total & 8 & 30 & 21 & 34 & 20 & 77 & 190 \\
\hline
\end{tabular}

Ket: B: Bayi, A: Anak, R: Remaja, D: Dewasa

Kepadatan merupakan nilai yang menunjukkan jumlah individu per satuan luas. Informasi mengenai kepadatan bekantan sangat penting sebagai dasar bagi pengelolaan habitat. Misalnya jika nilai kepadatan lebih tinggi dari daya dukung habitatnya, maka dapat menjadi pertimbangan sebagai dasar untuk: (1) restorasi habitat untuk meningkatkan daya dukung, atau (2) mengurangi sejumlah individu untuk dipindahkan ke habitat lain. Kepadatan poulasi bekantan di rawa gelam ini adalah 2,7 individu/hektar. Hasil ini lebih tinggi bila dibandingkan dengan Rabiati et.al. (2015) dengan kepadatan 0,81 individu/hektar di Suaka Margasatwa Kuala Lupak. Bekantan di rawa gelam dapat bertahan walaupun kualitas habitatnya menurun, hal ini menunjukkan bahwa bekantan memiliki tingkat adaptasi tinggi terhadap lingkungannya. Suwarto (2015) mengungkapkan bahwa jika bekantan terdapat pada habitat yang memiliki keterbatasan jenis sumber pakan yang tersedia, maka hal ini akan mendorong bekantan untuk beradaptasi dengan memanfaatkan sumber daya yang tersedia. Adaptasi ini merupakan salah satu strategi bekantan untuk bertahan hidup di habitat yang terisolasi dan terfragmentasi. 
Kepadatan populasi bekantan juga dilaporkan berbeda-beda di berbagai tempat sesuai dengan kondisi dan kualitas habitatnya. Di hutan bakau Taman Nasional Kutai, rata-rata kelompok Bekantan terdiri dari 21 individu (17-24 individu) (Bismark, 1995), di Taman Nasional Tanjung Puting sebanyak 6-16 individu (Bennet dan Sebastian, 1988), di Brunei terdiri dari 12-27 individu (Kern, 1984), di Gunung Palung terdiri dari 11-56 individu (Ruhiyat, 1986) dan di Taman Nasional Tanjung Puting sebanyak 3-17 individu (Yeager, 1989). Yeager dan Blondal (1992) menghubungkan antara kepadatan populasi Bekantan dengan kualitas habitat, dimana kepadatan populasi Bekantan mampu menjadi indikator kerusakan habitat, kategori tersebut yaitu: (1) sembilan individu/ $\mathrm{km}^{2}$ mengindikasikan habitat rusak berat, (2) 25 individu/ $\mathrm{km}^{2}$ mengindikasikan kerusakan habitat agak berat, (3) 33 individu $/ \mathrm{km}^{2}$ mengindikasikan habitat rusak sedang dan (4) 62,9 individu/ $\mathrm{km}^{2}$ mengindikasikan habitat rusak ringan. Kondisi habitat di lokasi penelitian jika dilihat dari kriteria tersebut termasuk ke dalam kategori habitat rusak agak berat.

\section{Nisbah Kelamin (Sex Ratio)}

Identifikasi jenis kelamin pada kelompok bekantan dilakukan berdasarkan perbedaan bentuk dan ukuran tubuh bekantan. Berdasarkan hasil identifikasi di lapangan, perbedaan jenis kelamin pada kelas umur remaja dapat diketahui, pada jantan memiliki hidung yang mulai tumbuh membesar sedangkan pada remaja betina hidung tumbuh meruncing atau mancung. Pada kelas umur dewasa terlihat hidung jantan tumbuh berukuran lebih besar dan menggantung, sedangkan pada betina tidak terjadi pertambahan ukuran hidung, namun antara betina remaja dan dewasa dapat dibedakan melalui ukuran tubuh. Pada kelas umur bayi dan anak sulit untuk diidentifikasi jenis kelaminnya. Berdasarkan hal tersebut maka diketahui nisbah kelamin bekantan di rawa gelam adalah 1: 1,8. Hal ini menunjukkan jumlah betina lebih besar dibandingkan jumlah jantan (Tabel 2).

Tabel 2. Nisbah kelamin bekantan di rawa gelam

Table 2. Sex ratio of bekantan in cajuputi swamp

\begin{tabular}{|c|c|c|c|c|c|}
\hline \multirow[b]{2}{*}{ Kelompok } & \multicolumn{2}{|c|}{ Jantan } & \multicolumn{2}{|c|}{ Betina } & \multirow{2}{*}{$\begin{array}{l}\text { Nisbah } \\
\text { Kelamin } \\
\text { Kelompok }\end{array}$} \\
\hline & Remaja & Dewasa & Remaja & Dewasa & \\
\hline 1 & 1 & 1 & 2 & 5 & $1: 3,5$ \\
\hline 2 & 3 & 4 & 2 & 4 & $1: 0,8$ \\
\hline 3 & 2 & 4 & 2 & 2 & $1: 0,6$ \\
\hline 4 & 0 & 4 & 0 & 16 & $1: 4$ \\
\hline 5 & 0 & 1 & 1 & 2 & $1: 3$ \\
\hline 6 & 5 & 7 & 5 & 20 & $1: 2,1$ \\
\hline 7 & 3 & 4 & 2 & 4 & $1: 0,8$ \\
\hline 8 & 6 & 8 & 6 & 22 & $1: 2$ \\
\hline 9 & 1 & 1 & 0 & 2 & $1: 1$ \\
\hline Total & 21 & 34 & 20 & 77 & \\
\hline $\begin{array}{l}\text { Nisbah Kelamin } \\
\text { Populasi }\end{array}$ & \multicolumn{2}{|c|}{55} & \multicolumn{2}{|c|}{97} & $1: 1,8$ \\
\hline
\end{tabular}

Nisbah kelamin bekantan di beberapa lokasi lain bervariasi, antara lain: 1:8,4 di Kinabatangan (Boonratana, 2000), 1:2,83 di Kabupaten Tabalong (Soendjoto, 2005), 1:3,9 di Kuala Samboja Kalimantan Timur (Atmoko et al., 2013), dan Rabiati et al., (2015) nisbah kelamin sebesar 1:3,09. Nisbah kelamin bekantan hasil penelitian ini terbilang paling kecil, dan berada dibawah rata rata, rata-rata dari hasil beberapa penelitian di atas 1: 4,5. Berdasarkan hal tersebut maka di lokasi penelitian diperlukan adanya treatment berupa pengkayaan populasi agar populasi yang ada dapat berkembangbiak dengan baik, sehingga diharapkan populasi tersebut tetap terjaga dan lestari.

Jika dilihat dari nisbah kelamin perkelompok di lokasi penelitian, hanya terdapat satu kelompok yang mendekati nisbah kelamin rata-rata dilokasi lain, yaitu pada kelompok 4 
dengan nilai sebesar 1:4. Kelompok ini terdiri dari 1 jantan dewasa, 16 betina dewasa, 5 bayi dan 6 anak (Tabel 1). Jika dilihat dari komposisi struktur umur maka kelompok ini memungkinkan untuk berkembang dengan baik jika kondisi habitat juga mendukung.

Angka nisbah kelamin pada primata sangat menentukan tipologi kelompok sosial pada satwa tersebut, sebagai contoh sistem harem akan mengarah kepada model kelompok multi-female. Pada umumnya mekanisme sistem "harem" dicirikan dengan perbandingan jumlah betina yang lebih banyak dari jumlah jantan, sedangkan pada sistem multi-male dicirikan dengan jumlah jantan lebih banyak dengan jumlah betina. Bennet dan Sebastian (1988) menjumpai Bekantan dengan sistem harem di hutan mangrove Sarawak, sedangkan dalam penelitiannya Bismark (2002) dijumpai kelompok bekantan yang mengarah kepada sistem multi-male di Taman Nasional Tanjung Puting.

\section{Struktur Umur}

Struktur umur Bekantan di rawa gelam menunjukkan tren populasi yang menurun. $\mathrm{Hal}$ ini terlihat dari kondisi jumlah bekantan anakan lebih sedikit jika dibandingkan dengan jumlah bekantan umur dewasa dan muda (Gambar 1). Alikodra (1990) mengemukakan bahwa jika individu berumur muda terlalu sedikit dibandingkan dengan jumlah individu yang berumur lebih tua, maka hal ini akan menunjukkan kemampuan reproduksi yang rendah. Tarumingkeng (1994) mengungkapkan bahwa struktur umur menurun dipengaruhi oleh beberapa faktor seperti kualitas habitat diantaranya ketersediaan pakan dan kandungan gizi pada pakan.

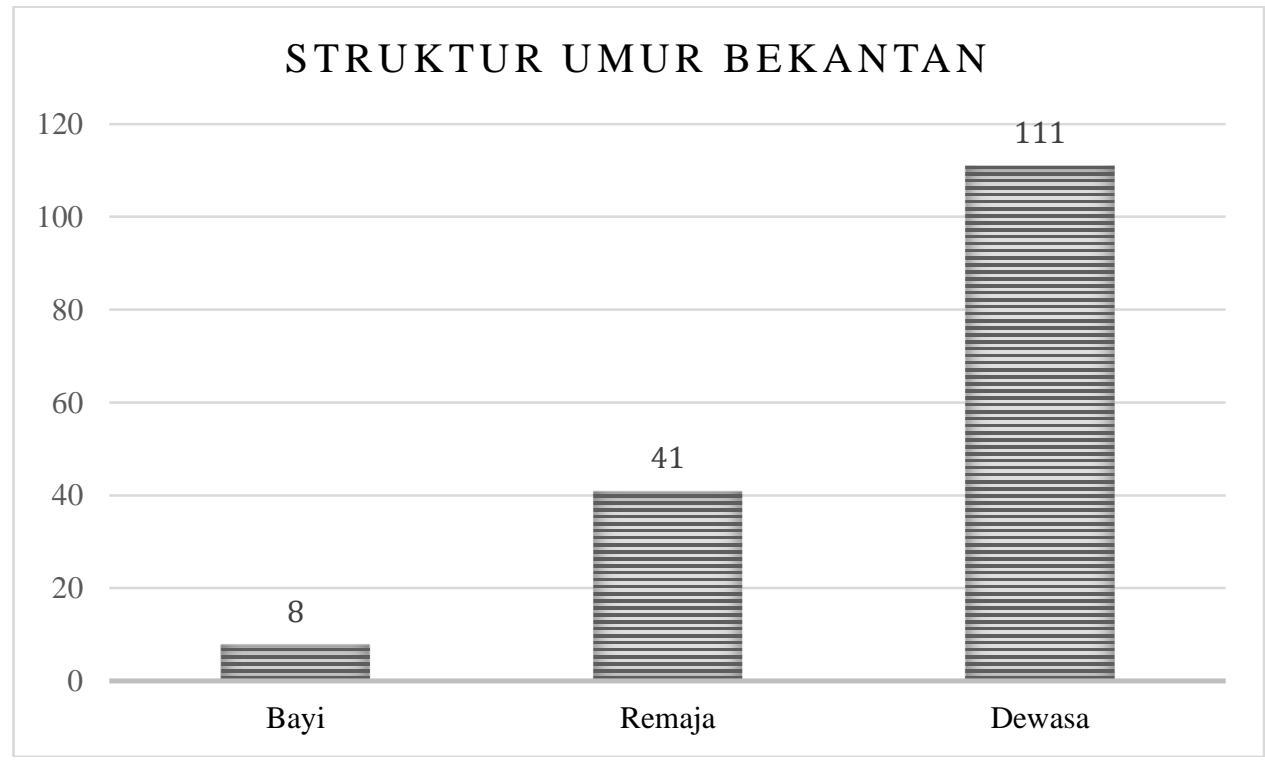

Gambar 1. Struktur umur bekantan di rawa gelam

Figure 1. Age Structure of bekantan in cajuputi swamp

Hasil analisa terhadap struktur umur Bekantan di lapangan secara umum memperlihatkan kondisi yang kurang ideal. Struktur umur tersebut menunjukkan bahwa keberlanjutan atau regenerasi populasi bekantan tidak berlangsung secara normal. Demikian juga apabila dilihat perkelompok, rata-rata kondisi tiap kelompok menunjukkan struktur umur menurun dimana dewasa lebih banyak dibanding anak atau yang berumur muda (Gambar 2). Diduga populasi dengan model struktur umur seperti ini akan terus menurun apabila kondisi lingkungan tidak berubah ke arah yang lebih baik (Tarumingkeng, 1994). Bekantan merupakan satwa yang peka terhadap lingkungannya. Menurut Fauzan et al., (2015) perubahan habitat dan aktivitas masyarakat dapat menyebabkan gangguan yang akan berdampak kepada penurunan kemampuan reproduksi bekantan untuk 
menghasilkan keturunan serta peningkatan peluang kematian pada umur anak (khususnya bayi).

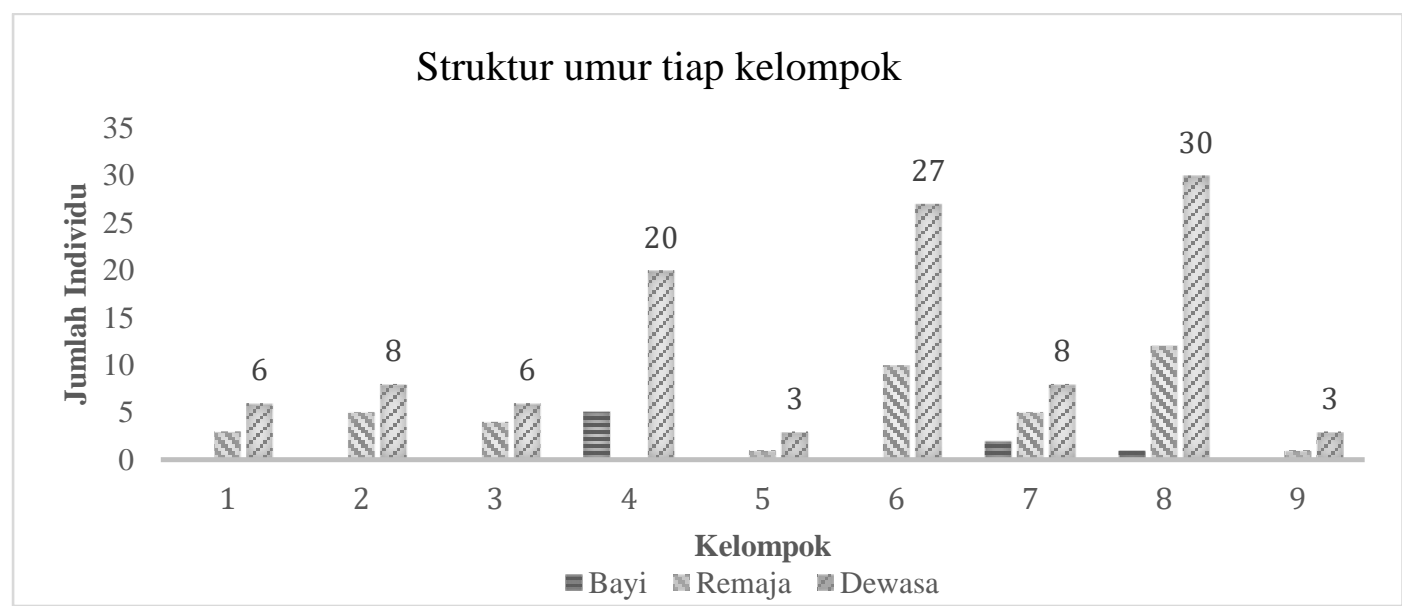

Gambar 2. Struktur umur bekantan setiap kelompok

Figure 2. Structure of bekantan's age for each group

\section{KESIMPULAN DAN SARAN}

Jumlah populasi bekantan di rawa gelam berdasarkan hasil penelitian berjumlah 190 individu terbagi ke dalam 9 kelompok, terdiri dari 8 bayi, 30 anak, 21 jantan remaja, 34 jantan deawasa, 20 betina remaja, dan 77 betina dewasa. Nisbah kelamin populasi bekantan di rawa gelam 1: 1,8 dan hanya satu kelompok yang mendekati rata-rata nisbah pada lokai lain, yaitu kelompok 4 dengan nisbah kelamin 1:4. Struktur umur populasi bekantan di rawa gelam menunjukkan struktur umur yang menurun. Hal ini terlihat dari kondisi jumlah bekantan anak lebih sedikit jika dibandingkan dengan jumlah bekantan umur dewasa dan muda.

\section{DAFTAR PUSTAKA}

Alikodra, H.S. (1990). Pengelolaan Satwa Liar. Bogor: Pusat Antar Universitas Ilmu Hayat Institut Pertanian Bogor.

Alikodra, H.S. (2002). Pengelolaan Satwa Liar Jilid 1. Bogor: Yayasan Penerbit Fakultas Kehutanan IPB.

Alikodra, H.S., R. Srimulyaningsih. (2015). Bekantan Melawan Kepunahan. In H.S. Alikodra, Efransyah, M. Bismark (Eds.), Populasi bekantan di Rawa Gelam. Bogor: IPB Press.

Atmoko T, Mardiastuti A, Iskandar E. (2013). Struktur Kelompok dan Penyebaran Bekantan (Nasalis larvatus Wurmb) di Kuala Samboja, Kalimantan Timur. Di dalam: Oka NP, Achmad A, Maulany RI, Asrianny (editor). Prosiding Seminar Ilmiah Nasional Ekologi dan Konservasi; 2013 Nov 20-21; Makassar. Makassar (ID): Fakultas Kehutanan Universitas Hasanuddin, Balai Taman Nasional Bantimurung, Masagena Press. 29-34.

Bennet, E.L., A.C. Sebastian. (1988). Social Organization and Ecology of Proboscis Monkeys (Nasalis larvatus) in Mixed Coastal in Sarawak. Int. J. of Primatol. 9(3), 233-255.

Bismark, M. (1986). Habitat dan Tingkah Laku Bekantan (Nasalis larvatus geoffr) di Suaka Margasatwa Tajung Puting, Kalimantan Tengah. Laporan LPH No. 375.

Bismark, M. (1995). Konsumsi Pakan Bekantan dalam Penangkaran. Jurnal Pen. Hut. 589, 2738. 
Bismark, M. (2002). Biologi Konservasi Bekantan (Nasalis larvatus). Bogor: Pusat Penelitian dan Pengembangan Hutan dan Konservasi Alam.

Bismark, M. (2005). Model Pengukuran Biomasa Populasi Primata. Jurnal Pen. Hut. Dan Kons. Alam. 2(5), 491-496.

Boonratana, R. (2000). Ranging behaviour of Proboscis Monkeys (Nasalis larvatus) in the lower Kinabatangan, Northern Borneo. Int. J. of Primatology, 21(3), 497-518.

Fauzan, N., Kaspul., A. Naparin. (2015). Struktur Populasi Bekantan (Nasalis larvatus) di area Gunung Batu Sawar Kecamatan Hulu Sungai Tengah. Prosiding Seminar Nasional Pendidikan Biologi FKIP UNS.

IUCN. (2021). Red List of Threatened Species: Proboscis Monkey. 19 Januari 2021, diunduh dari https://www.iucnredlist.org/species/14352/17945165.

Kern, J.A. 1984. Observation on The Habit of The Proboscis Monkey, Nasalis larvatus (Wurmb), Made in The Brunei bay Area. Borneo Zoologica, 49(11), 183-192.

MacKinnon. (1987). Conservation status of primates in Malaysia, with special reference to Indonesia. Primate Conservation, $8: 175-183$.

Prastowo, A. (2011). Metode Penelitian Kualitatif dalam Perspektif Rancangan Penelitian. Jogjakarta: Ar-Ruzz Media.

Rabiati, M., A.P. Kartono, B. Masyud. (2015). Populasi Bekantan (Nasalis larvatus) di Suaka Margasatwa Kuala Lupak, Kalimantan Selatan, Indonesia. Media konservasi, 20(3), 242251.

Ruhiyat, Y. (1986). Premilinary study of proboscis monkey (Nasalis larvatus) in Gunung Palung Nature Reserve West Kalimantan, Studies on Asian nonhuman Primates. Kyoto: Kyoto Univ. Primates Resc. Inst.

Santosa, Y., F Sitorus. (2008). Pendugaan Parameter Demografi dan Pola Penyebaran Spasial Walabi Lincah (Macropus agilis papuanus) di Kawasan Taman Nasional Wasur Studi Kasus di Savana Campuran Udi-Udi Seksi Pengelolaan III Wasur, Papua. Media Konservasi, 2(13):65-70.

Sha, J.C.M., H. Bernard, S. Nathan. (2008). Status and Conservation of Proboscis Monkeys (Nasalis larvatus) in Sabah, East Malaysia. Primate Conservation 2002(23), 107-120.

Soendjoto MA. 2005. Adaptasi Bekantan (Nasalis larvatus Wurmb) Terhadap Hutan Karet: Studi kasus di Kabupaten Tabalong, Kalimantan Selatan. (Disertasi). Institut Pertanian Bogor, Bogor.

Sugiyono. (2010). Metode Penelitian Kuantitatif Kualitatif dan R\&D. Alfabeta. Bandung.

Suwarto. (2015). Kesesuaian habitat bekantan (Nasalis larvatus) di hutan mangrove Taman Nasional Kutai. (Tesis). Institut Pertanian Bogor, Bogor.

Supriatna, J., E.H Wahyono. (2000). Panduan Lapangan Primata Indonesia. Jakarta: Yayasan Obor Indonesia.

Tarumingkeng, R. C. (1994). Dinamika Populasi Kajian Ekologi Kuantitatif. Jakarta: Pustaka Sinar Harapan dan Universitas Kristen Krida Wacana.

Tobing I.S.L. 2008. Teknik Estimasi Ukuran Populasi Suatu Spesies Primata. Vis Vitalis (1) : $43-52$

Yeager, C.P. (1989). Feeding Ecology of The Proboscis Monkey (Nasalis larvatus) Int. J. of Primatology, 10(6), 497-529. Retrieved from http://www.scholar.google.com.

Yeager, C.P., T.K. Blondal. (1992). Conservation Status of Proboscis Monkey (Nasalis larvatus) at Tanjung Puting National Park, Kalimantan Tengah, Indonesia. Forest Biology and Conservation in Borneo. Center for Borneo Studies Publication, 2, 220-228.

Zainudin, A. Rezeki. (2016). struktur populasi bekantan (nasalis larvatus) di pulau curiak kabupaten barito kuala Kalimantan selatan. Prosiding Symbion (Symposium on Biology Education), Prodi Pendidikan Biologi, FKIP, Universitas Ahmad Dahlan, 27 Agustus 2016. Retrieved from http://www.scholar.google.com. 